\title{
Aprendiendo idiomas en línea en el tiempo libre ${ }^{1}$
}

Online language learning as a spare time activity

\author{
Shafirova Liudmila \\ Universitat Pompeu Fabra \\ liudmila.shafirova@upf.edu \\ Dr. Daniel Cassany \\ Universitat Pompeu Fabra \\ daniel.cassany@upf.edu
}

\section{Resumen}

El uso de las tecnologías de la información y la comunicación (TIC) afecta diferentes espacios de nuestra vida, lúdicos y profesionales, aunque a veces sea difícil trazar una frontera entre ambos campos. Presentamos a varios jóvenes que usan los espacios lúdicos en línea para aprender idiomas en su tiempo de ocio. Aunque se trate de aprendizajes informales que ocurre fuera del aula, la influencia que pueden tener en la educación reglada es indiscutible. Este trabajo se sitúa en el marco conceptual etnográfico de las nuevas literacidades y del aprendizaje social y situado, con un estudio de casos múltiples de cinco jóvenes españoles y dos turcos que aprenden ruso fuera del aula. Sus experiencias ilustran con detalle cómo los aprendices desarrollan prácticas diversas y sofisticadas según sus intereses socioculturales y cómo conectan su ocio con los recursos que ofrece la red, integrando el uso del idioma en sus rutinas diarias e incrementando su aprendizaje.

\begin{abstract}
The use of information and communication technologies (ICT) affects different parts of our lives, such as leisure and working areas, however sometimes it is difficult to draw a border between them. Moreover, we present a few young people who use the ludic online spaces in order to learn languages in their spare time. Although informal learning occurs outside the classroom, the influence it can produce on formal education is undeniable. Our study is situated in the ethnographic conceptual framework of new literacies and social and situated learning, based on a multiple case study of five young Spanish participants and two Turks learning Russian language outside the classroom. Their experiences can be a great example of how learners develop different and sophisticated practices according to their sociocultural interests and how they connect their hobbies with the Internet resources, integrating the use of language in their daily routines and improving their language skills.
\end{abstract}

\footnotetext{
${ }^{1}$ Recibido: 24/04/2017 Evaluado: 30/06/2017 Aceptado: 30/06/2017
} 
Palabras clave: aprendizaje informal; las nuevas literacidades; aprendizaje en línea; aprendizaje de idiomas.

Keywords: informal learning; new literacies; online learning; language learning.

\section{Introducción}

Sin duda las prácticas sociales para aprender idiomas de manera informal han aumentado con Internet, puesto que encontramos hablantes o materiales de muchos idiomas extranjeros sin la necesidad de viajar a otro lugar. La tecnología digital distribuye el conocimiento de modo más inmediato, barato y ubicuo, lo cual también acelera la globalización y los contextos para usar las lenguas extranjeras. Aprendemos idiomas cuando jugamos a videojuegos (Thorne, 2008), usamos redes sociales (Buck, 2012), leemos fan-fiction (Cassany y Hernández, 2011), escribimos en blogs (Lepänen, 2007) o formamos parte de una comunidad, como scanlators: Comunidades de fans que traducen manga de origen japonés de modo amateur y colaborativo (Valero-Porras \& Cassany, 2015) o fan-subbers: Comunidades de fans que subtitulan sus productos audiovisuales favoritos de modo amateur y colaborativo. (Zhang \& Cassany, 2016). Todos estos ejemplos están conectados con la diseminación de las TIC y sus diferentes géneros discursivos, contenidos y usos, que incrementan las oportunidades de aprender idiomas. Muchas de estas prácticas son informales; los participantes tienen interés en las propias actividades específicas (un videojuego, un fanfic, un cómic, un contacto personal) además de la posibilidad de conocer una cultura y una lengua extranjera.

Al ser el inglés la lengua dominante (Top Ten Internet Languages, 2015), también es la que ha merecido más estudios sobre el aprendizaje informal. Por ello, para este estudio hemos elegido el ruso, que carece de estudios de este tipo y que ofrece otras peculiaridades: 1) es un idioma tipológicamente y geográficamente alejado; 2) tiene menos presencia en la red; 3) se escribe con otro alfabeto (cirílico), lo cual dificulta la navegación por la web y el acceso a los recursos, y 4) suele ser la tercera o cuarta lengua de los aprendices -que han aprendido previamente otros idiomas (inglés, francés)-, lo cual crea contextos sugerentes para la aparición de varios temas actuales de investigación como el plurilingüismo, el translanguaging y el code-switching.

Nuestros datos proceden de un TFM, por lo que, para más información sobre la metodología de recogida de datos se puede consultar el Trabajo de Fin de Máster (TFM) del Máster en Estudios del Discurso, de la Universitat Pompeu Fabra, con orientación de investigación, realizado por L. Shafirova y dirigido por D. Cassany (Shafirova, 2016). y se recogieron entre enero y mayo de 2016, aunque hemos incluido entrevistas realizadas con posterioridad. En total nos basamos en 10 entrevistas en profundidad (7 exploratorias y 3 de seguimiento), realizadas por internet a 7 informantes, en español, ruso o inglés, con un total de 286 minutos de audio y 18.566 palabras transcritas. Es un estudio de siete casos con metodología cualitativa y una perspectiva etnográfica virtual. Los 7 jóvenes informantes aprenden ruso en línea desde dos países diferentes: España y Turquía. Nos parece enriquecedor poder comparar datos procedentes de dos países lejanos con lenguas y culturas distantes, entre sí y con relación al ruso. Esperamos que los ejemplos y los comentarios aportados muestren las diversas prácticas de aprendizaje informal y en línea que siguen hoy muchos jóvenes, con sus características 
más relevantes. Asumimos que los recursos en línea permiten a estos informantes superar la falta de hablantes y de materiales en la lengua meta en sus contextos geográficos, de modo que les ayudan a cruzar la barrera cultural en el aprendizaje del idioma (Bogomolov, 2008).

Finalmente, consideramos que investigar sobre el aprendizaje informal de idiomas en la red es una estrategia relevante, porque: 1) explora prácticas actuales -y de futuro- de aprendices jóvenes; 2) muestra cómo se usan realmente las TIC en contextos reales; 3) muestra cómo los sujetos aprenden idiomas por su cuenta sin profesor, empleando recursos no pensados para la enseñanza de lenguas, y 4) apunta diversas pistas sobre cómo se podrían integrar o similar estas prácticas naturales y autogeneradas en un espacio más formal como el aula.

\section{Aprendizaje informal y en línea}

Explicamos brevemente cómo entendemos el aprendizaje informal y en línea, en el contexto de aprender idiomas extranjeros, por contraposición al aprendizaje formal, con currículum, planificación, libros de texto, docente, horarios, etc.:

a) El aprendizaje informal está centrado en el aprendiz y no tiene una estructura preestablecida; no hay niveles o bloques construidos por el programa educativo o por el profesor; el aprendiz es libre y decide qué quiere aprender y cómo.

b) Aprender idioma no siempre es el primer objetivo de la actividad. Así, Thorne, Black y Sykes (2009) analizan la interacción entre un ruso y un angloparlante en un videojuego o MMO (Massive Multiplayer Online Game): el angloparlante, que no sabía ruso, se esforzó preguntando palabras y frases en ruso a otro conocido suyo, que hablaba dicho idioma, para poder mantener el contacto con el jugador rusoparlante. Este mismo jugador angloparlante mostró luego una fuerte motivación por aprender ruso con el objetivo de poder jugar con los rusoparlantes en World of Warcraft. De modo que el aprendizaje del idioma no siempre es la meta final.

c) La identidad del aprendiz se construye de diferente manera. En el aula el aprendiz adopta el rol de "inexperto", mientras que el profesor asume el de "experto". Sin embargo, en el aprendizaje informal y en línea el aprendiz puede desempeñar varios roles (moderador, animador, interlocutor, etc.), lo cual resulta mucho más participativo y motivador.

d) Los aprendices pueden participar al mismo tiempo en varios espacios en la web (affinity spaces), que se describen como espacios colaborativos, que distribuyen el conocimiento. Gee (2004) introduce el concepto de affinity space que aborda un espacio (físico, virtual o una mezcla de los dos) en el que las personas puedan interactuar, compartiendo prácticas, ideas, objetivos e intereses, y así adquieren conocimientos. Estos tiene también varias características específicas: están distribuidos entre los participantes, son más tácitos y pueden tener varios grados de especialidad. Gee (2004) ejemplifica este concepto con un portal de los fans de videojuegos tipo RTS (Real-Time Strategy Games), en el que los jugadores obtienen noticias, reseñas de juegos, guías estratégicas, mapas y escenarios, mientras participan en diferentes fórums. 
e) Aprender en línea requiere desarrollar nuevas literacidades (Knobel \& Lankshear (2006). Para estos autores, las nuevas alfabetizaciones o literacidades no solo tienen una apariencia diferente (como la pantalla, los píxeles o los códigos digitales), sino que poseen un nuevo núcleo o "ethos" que se considera más "colaborativo", "participativo" y "distribuido" que en las literacidades convencionales, y que fomenta mentalidades y actitudes diferentes.

f) Los espacios virtuales suelen ser multimodales (con vídeo, fotos, elementos gráficos; Knobel \& Lankshear, 2006) y multilingües, puesto que pueden incorporar varias lenguas y variedades (Androutsopoulos, 2014). Nos referimos a ello más adelante.

Al recoger los datos empíricos hemos observado que los aprendices trataban de realizar varias prácticas en ruso conectándolas con su ocio: leer y traducir las recetas rusas, leer las noticias, ver los dibujos animados y escuchar la música. Nuestro primer caso se centra en el uso de la música rusa en el siguiente apartado.

\section{Aprender con música}

Tres aprendices afirman usar la música rusa para aprender el idioma. El primero, Joan, tiene 21 años y estudia filología en la Universidad de Barcelona, con ruso y francés como materias de grado. Habla catalán, español, francés, inglés y ruso (nivel B1). Ha elegido el ruso porque es "una lengua exótica", con alfabeto no latino, y por su interés acerca de la historia y cultura rusas, específicamente la revolución del siglo XX. A Joan le gusta escuchar hip-hop ruso: conoce varios grupos, baja sus canciones al móvil y las escucha en su día a día. Así empezó a buscar su música:

Bueno, es una cosa curiosa, bueno, empecé una vez investigando por Internet, no, por ejemplo, en Google, encontré una web que se llama Rap.ru. Y entonces, es como un portal de rap en Rusia, y allí pues, he descubierto cantantes rusos de rap, y claro, también me ayudaba a leer, porque eran explicaciones cortas sobre un álbum, un nuevo álbum, no sé qué, te explicaban, y tú descubrirás otro cantante, otro álbum, todo eso.

Aunque tenga numerosos conocidos rusos, Joan prefiere investigar por su cuenta. Sus amigos tienen otros gustos, alejados del hip-hop. Buscando por su cuenta, Joan encontró el sitio Rap.ru, con artículos y noticias en ruso sobre el rap: 


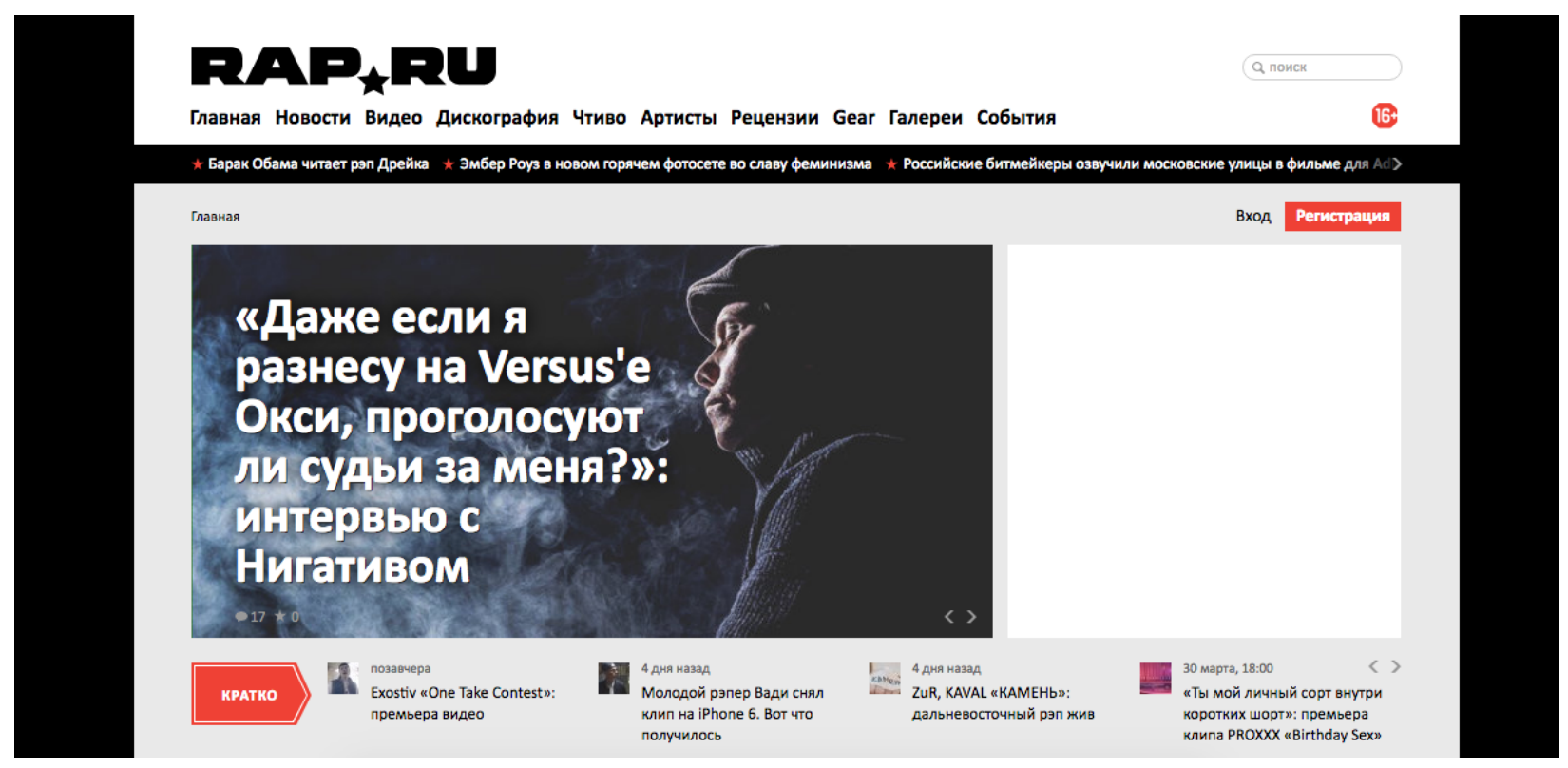

Figura 1: Captura de pantalla del sitio Rap.ru con la música favorita de Joan

Este sitio actúa como un espacio de afinidades en el que Joan, pese a ser extranjero y un usuario pasivo y no identificado, aprovecha los recursos que le interesan: busca la música, la baja, la escucha y lee artículos sobre el rap ruso, lo cual le obliga a desarrollar habilidades diferentes.

Aldo tiene 23 años, vive en Granada y estudia Derecho y Relaciones Internacionales. Le motivó a aprender ruso su propio interés en la literatura y la historia rusas. Lleva estudiando este idioma casi 3 años: durante dos meses siguió un curso presencial, pero el resto del tiempo lo ha estudiado por su cuenta. Afirma desconocer su nivel de competencia, pero puede mantener una conversación fluida y leer periódicos. A Aldo normalmente le gusta escuchar rock ruso. Descubre cantantes y piezas por las recomendaciones de sus amigos, ya que comparten gustos musicales. Escuchando y leyendo los estribillos de las canciones, afirma que se da cuenta de que memoriza nuevas palabras:

Pues, a veces sí, a lo mejor el estribillo, por el estribillo suele ser más lo que me queda en la cabeza. El estribillo de la canción suele ser la parte que yo intento memorizar en ruso. Y a lo mejor si hay alguna palabra en el estribillo pues a lo mejor, busco esta palabra, no sé, para que me quede mejor, no sé.

Aldo lee y escucha las canciones a través de la red social VK: análogo ruso de Facebook, con la diferencia de VK acepta descargar, subir y compartir mucho contenido pirateado. VK contiene una gran cantidad de películas y dibujos animados doblados al ruso y en la lengua original, así como música de todas partes del mundo. Este contenido se puede encontrar mediante la búsqueda directa o entrando en los sitios de algún grupo de interés. Además, los noticieros más grandes de Rusia tienen sus grupos en $\mathrm{VK}$, donde postean todas las noticias, la cual le facilita la búsqueda de las canciones y del texto. 


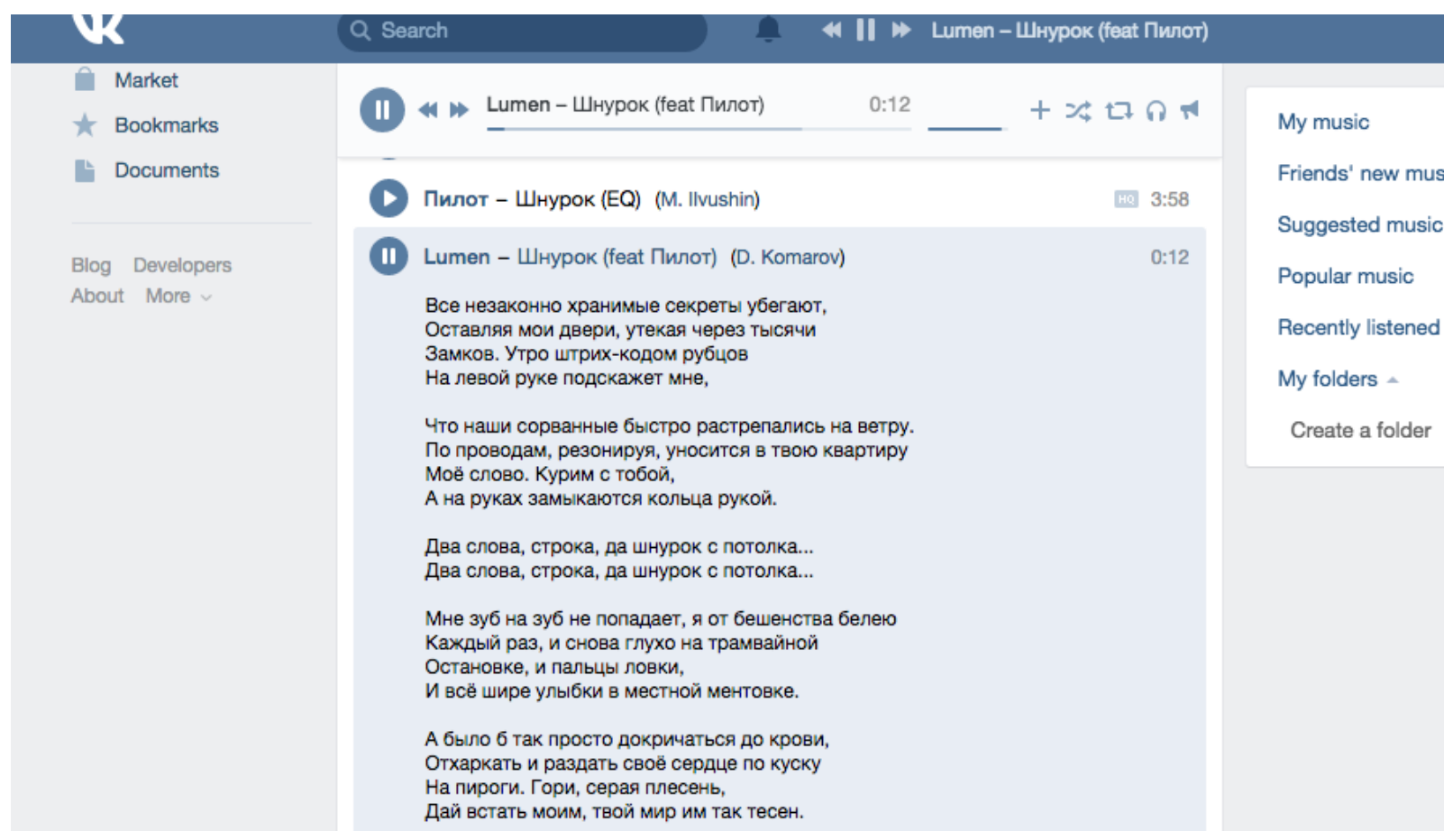

Figura 2: Captura de pantalla del sitio web VK con la música rusa favorita de Aldo

Nuestro tercer aprendiz se llama Burak, tiene 40 años y vive en Ankara. Trabaja como ingeniero informático y estudia ruso desde hace siete meses, siguiendo algunos cursos reglados, aunque ve el aprendizaje del ruso como un hobby. Le interesa mucho la cultura rusa y, al empezar a aprender el idioma, se enamoró de la música folclórica rusa. Ahora a menudo escucha este tipo de música: baja las canciones, las traduce usando diccionarios digitales y trata de memorizar la letra. Dice que le apasiona una cantante en particular, Marina Devyatova, cuyos posts sigue y trata de entender en la red social rusa VK:

I use VKontakte to follow Marina Devyatova page, and when she goes to the concerts in Russia or other countries, she posts some pictures in Russian, so I try to understand in Russian.

Actually I use Vkontakte only for following Marina Devyatova, I am a stoker! 


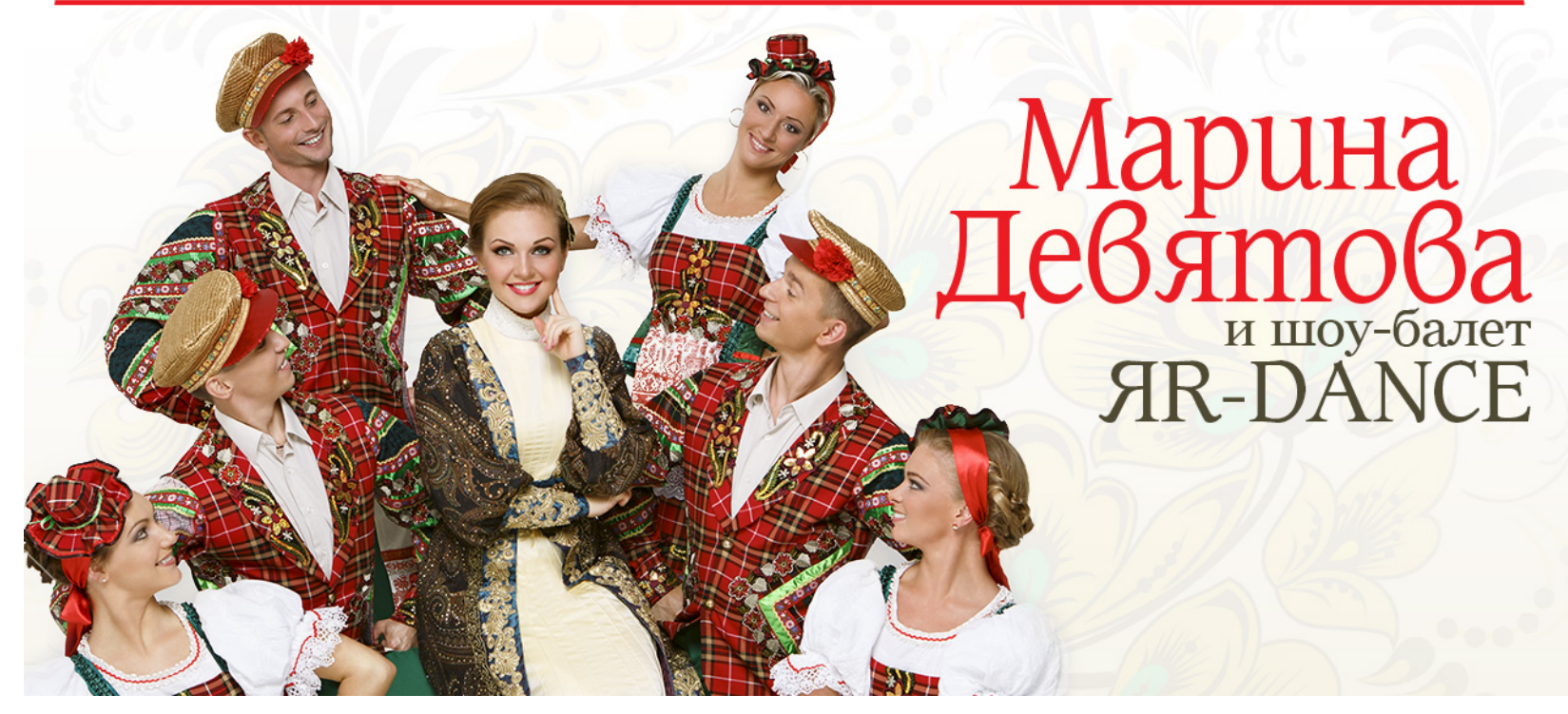

Figura 3: Foto recuperada del sitio web de Marina Devyatova

En resumen, el interés por la música rusa genera diferentes prácticas como: buscar los grupos preferidos y leer sobre ellos, leer los textos de las canciones y traducirlas en el diccionario, seguir a una cantante favorita y leer sus publicaciones, escuchar las canciones y tratar de entenderlas o repetir el estribillo y memorizarlo. Todas estas prácticas ocurren alrededor del interés por la música, en la red y fuera del aula. Además, los aprendices incorporan estas prácticas a su rutina diaria, ya que bajan las canciones al móvil y las pueden escuchar en el cualquier lugar. Suponemos que para obtener información sobre sus grupos y cantantes favoritos, ellos tenían que entrar a los sitios para hablantes nativos. Esto requiere unos saberes tácitos de usar las TIC en el mundo rusoparlante: como buscar y validar la información musical (con cierto nivel de especificidad) en ruso, abrir una cuenta o perfil individual en la red social rusa VK (y aportar un mínimo de información personal), saber usar las aplicaciones, comandos y recursos de VK para escuchar, leer y bajar las canciones y/o seguir a un artista. Consideramos que estas habilidades específicas de manejar Internet en ruso en espacios rusoparlantes forman parte de las nuevas literacidades.

\section{Aprendizaje multimodal y plurilingüe}

Dos características relevantes del aprendizaje en línea según los datos de nuestro estudio son la multimodalidad y el plurilingüismo. Con multimodalidad nos referimos al hecho de que en la red los textos integran varios modos de representar la información, como el audio, la imagen (estática o en movimiento), la animación gráfica, la escritura, el habla, etc. (Rowsell \& Walsh, 2011). Todos los informantes afirman haber usado vídeos de diferentes formatos para mejorar su competencia oral en ruso, de manera frecuente y beneficiosa. La razón fundamental es que la imagen contextualiza el habla 
oral y facilita la comprensión por diferentes motivos: 1) los gestos, la prosémica (el uso del espacio en la interacción), la kinésica (el acento, la entonación y el ritmo del habla) y las expresiones faciales de los hablantes facilitan el entendimiento del mensaje (Hoven, 1999); 2) todas estas cuestiones difieren en distintas culturas y lenguas (Kellerman 1992 y Hurley 1992), por lo que el aprendiz accede a las expresiones características de los hablantes reales con estas muestras gráficas (como se cita en Hoven, 1999: 90), y 3) el vídeo muestra el contexto pragmático del uso verbal (cómo se utiliza la lengua en cada la situación) y facilita por ello el proceso del aprendizaje (Abrams, 2014).

Una segunda característica del aprendizaje de idiomas en línea, según los datos, es el plurilingüismo o la utilización del idioma materno u otros para aprender. Según Nussbaum (2014), el uso de la primera lengua para aprender la segunda puede ser beneficioso para el estudiante. Esta autora presenta también el concepto de translanguaging, que presupone no sólo una interacción con el uso de una lengua para aprender la otra, sino una forma híbrida de desarrollar prácticas lingüísticas aprovechando los recursos de diferentes idiomas. Androutsopoulos (2014) también describe varios internautas que usan diferentes idiomas para comunicarse con distintos auditorios en Facebook, mezclando así varios idiomas en su "muro" de esta red social. En esta misma línea, uno de nuestros informantes afirmaba ver y seguir algunas obras audiovisuales con subtítulos en un idioma distinto del idioma original del audio (la lengua meta) y del de su lengua maternal.

Pero el dato más revelador de nuestro estudio es que cuatro aprendices de los siete informantes afirman seguir activamente diferentes dibujos animados (DA) para aprender ruso y que uno de ellos los sigue combinando dos lenguas entre el audio y los subtítulos. Por "seguir" DA nos referimos a que estos informantes reiteradamente visualizan los episodios breves sucesivos de sus series favoritas de DA, y que, por ello, podemos concluir que han incorporado en su rutina diaria el consumo frecuente de DA en ruso para divertirse -y también para aprender ruso-. Veamos esta situación con más detalle.

\section{Dibujos animados en el aprendizaje de ruso}

Tenemos dos casos diferentes de la práctica de ver dibujos animados en línea. Un caso se centra en unos dibujos animados de producción rusa (Masha y el Oso) y el otro en los dibujos animados de producción norteamericana (Adventure Time, The Simpsons). Describiremos los dos casos para mostrar que prácticas multimodales y multilingües realizan los participantes.

Los dibujos de Masha y el Oso (con el título original ruso de Maша и Медведь, con romanización: Masha i Medved') son una serie de televisión infantil, animado en 3D, basada en un cuento folclórico tradicional ruso; consiste en 56 episodios, y todos están disponibles en YouTube en ruso. Este canal tiene más de 6 millones de seguidores y más de 8 mil millones de visualizaciones. Tres informantes afirman seguir esta serie aunque con diferente intensidad. Los visualizaban normalmente sin subtítulos, con el audio original en ruso, tratando de entenderlo por el contexto dibujado y por los rasgos kinésicos -que están muy marcados, al tratarse de dibujos esquemáticos y exagerados-.

Sin duda, la mayor fan de estos dibujos animados es Ester, una profesora de inglés que vive en Cataluña, con estudios universitarios de traducción y lengua rusa, aunque ahora aprovecha los medios 
digitales para no olvidar ese idioma. Ester trató de mirar diversas películas originales rusas, pero le parecieron muy difíciles de entender, ya que se hablaba rápido. Luego encontró un episodio de Masha y el Oso en YouTube, que le pareció mucho más asequible:

Sí, sí, me gusta ver los dibujos animados en ruso, porque ellos [los protagonistas de los dibujos] hablan lento y aunque yo no lo entiendo todo, puedo captar el sentido general (original en ruso, traducción nuestra).

Como dice Ester, en estos dibujos animados se habla más lento que en las películas con actores reales, y esto le facilita la comprensión audiovisual. Además, las imágenes del dibujo ayudan a captar el sentido, ya que Ester dice que es un dibujo "claro y fácil", en el que uno de los personajes casi nunca habla. De este modo, cuando hemos preguntado a Ester si las imágenes ayudan a comprender el vídeo, ella contestó: "Desde mi punto de vista, ayudan un montón” (original en ruso, traducción nuestra).

Además, Ester desarrolló su propia estrategia de aprendizaje para mejorar su comprensión audiovisual de Masha y el Oso: suele mirar los episodios sin subtítulos, tratando de comprender el audio hablado con la ayuda de la imagen y del contexto, visualizando varias veces cada escena cada cierto tiempo:

Yo trato de ver los capítulos más de una vez. Me parece que cuanto más lo veo, más palabras entiendo. Sí, vuelvo a mirar un capítulo, por ejemplo, después de dos semanas. Me parece que con la repetición es posible aprender, aunque aun no entiendo todas las palabras (original en ruso, traducción nuestra).

Así que la repetición del visionado de capítulos cada determinado tiempo es una estrategia clara para aprender el léxico nuevo y entender mejor el contenido audiovisual. Vemos también que aprovecha sabiamente la multimodalidad del producto y sus características gráficas, tratando de entender el sentido general del dibujo animado sin traducir cada palabra en concreto.

Aldo, nuestro estudiante granadino, además de escuchar el rock ruso -como comentamos más arribatambién mira sus dibujos animados favoritos en ruso. A diferencia de Ester, mira los DA norteamericanos doblados al ruso o subtitulados en ruso. En el momento de la primera entrevista Aldo miraba Adventure Time doblado al ruso, porque le gustaba este DA y quería practicar la lengua de esta manera. Sin embargo, en la segunda entrevista Aldo afirmó que entonces miraba otra serie, The Simpsons, también con subtítulos en ruso. Según sus palabras, durante aproximadamente tres meses Aldo visualizó casi cada día un capítulo de The Simpsons.

Sin duda nos interesó esta práctica lingüística multimodal y plurilingüe tan particular, realizada a lo largo de un periodo de tiempo tan largo, de modo que había logrado incrustarla en su rutina diaria. Cuando le preguntamos por qué había elegido ver DA norteamericanos para aprender ruso -lo cual nos pareció sorprendente-, Aldo mencionó que en la red no hay tantos recursos accesibles para aprender ruso, comparado con el inglés. Además, él conocía bien la trama de Adventure Time y de The Simpsons, por lo que estos DA le permitían ver como se usa la lengua en unos contextos determinados, es decir, lo veía como un aprendizaje más situado y significativo para él: 
I: ¿Te ayudaba a aprender nuevas palabras y formas gramaticales también?

A: Formas gramaticales, gramática no creo, pero sí modismos, palabras y modismos sí. Por ejemplo, cuando tú ves en la calle en una conversación dos personas hablando o en un dibujo animado hablando, tú ves que el idioma fluye, es como se va en movimiento. Entonces para verla en movimiento, no es algo estático y puedes ver de verdad como el idioma funciona. La gramática, tú perfectamente la puedes estudiar, tú por tu cuenta, sí. Pero para ver cómo funciona la lengua necesitas ir más allá.

Aparte, Aldo tenía una estrategia de comprensión audiovisual distinta de Ester. Seguía The Simpsons en una web de pago que tenía como audiencia principal a rusoparlantes que quieren aprender inglés. De esta manera, Aldo podía mirar The Simpsons con el audio en inglés y elegir entre dos subtítulos (inglés o ruso). Normalmente ponía los subtítulos en ruso y los leía mientras visualizaba el vídeo del episodio, pero cuando no entendía una palabra, Aldo paraba el vídeo, cambiaba los subtítulos al inglés y así traducía y comprendía las palabras desconocidas. De este modo, vemos que Aldo usaba el idioma inglés para reforzar el ruso, traduciendo de inglés a ruso y del ruso al inglés simultáneamente, en una forma particular de translanguaging, en su vida diaria.

\section{Conclusiones}

Aunque nuestros datos sean forzosamente limitados y diversos, sin poder de generalización, veamos ahora algunas características comunes de las prácticas de aprendizaje de ruso de los informantes estudiados:

- Aprendizaje autodirigido. Los aprendices estudiados siguen sus intereses personales para incrementar su acceso a hablantes y materiales de la lengua meta. Esos intereses son diversos y abarcan todo tipo de producciones culturales, como la música de diferentes estilos o las producciones audiovisuales favoritas. No importa la valoración social o el estatus de estas producciones: ni a Aldo ni a Ester ni al resto de informantes les preocupa que la música rock o los dibujos animados sean obras de alta cultura o no.

- Aprendizaje múltiple. Los informantes no solo aprenden la lengua rusa, sino también a manejar la red en ruso y a gestionar varios productos digitales (audios, vídeos) y repositorios y redes sociales (VK, YouTube, etc.), lo cual, según el planteamiento de las nuevas literacidades, es una nueva manera de aprender, más natural y contextualizada (Knobel \& Lankshear 2015).

- Aprendizaje activo. El aprendizaje del idioma que realizan nuestros informantes utiliza diversas destrezas lingüísticas (comprensión oral, lectura) y tiene un carácter activo y dinámico. Los aprendices escuchan música o ven dibujos animados con un grado elevado de conciencia de estar aprendiendo, por lo que evalúan su nivel de comprensión y toman decisiones estratégicas al respecto. Pueden escuchar varias veces una misma canción, buscar su estribillo en la red y traducirlo o utilizar diversos recursos para encontrar el significado de un vocablo nuevo. De igual modo, eligen el audio y el subtítulo más adecuado de los DA para obtener la mayor comprensión en 
ruso, mientras realizan una actividad favorita en su tiempo libre y aprovechando su conocimiento previo de otras lenguas que puedan resultar útiles.

- Apropiación de prácticas. Los aprendices desarrollan rutinas continuadas de interacción con los materiales de la lengua meta, de modo que llegan a integrar esta nueva práctica en su ocio cotidiano. Este hecho prueba que se trata de una actividad importante, que tiene impacto tanto en sus vidas como en su competencia de la lengua meta. En algunos casos (graduados que terminaron los estudios, limitación de recursos, falta de disponibilidad para asistir a cursos) estos recursos son útiles para mantener el contacto con la lengua meta, puesto que se trata de un idioma lejano y no tan presente en su día a día.

Veamos ahora algunas características propias del aprendizaje de idiomas extranjeros en línea y en contextos informales, también según los datos expuestos:

- Acceso y producción cultural. El acceso fácil y gratuito a los recursos de la red es una característica fundamental de este tipo de aprendizaje. Los informantes escuchan música y ven vídeos porque los han encontrado en la red con facilidad. Es una cuestión de material disponible en la red, pero también de producción cultural en el idioma de estudio. Aldo ve Adventure Time o The Simpsons porque no ha encontrado otros DA en ruso que le gusten - lo cual sugiere que ha revisado la producción rusa de DA, que ha descartado Masha y el oso (que está disponible en la red) y que, al no haber nada de su gusto, ha preferido ver unos DA de otra cultura en lengua rusa-.

- Multimodalidad. Como hemos visto, los aprendices aprovechan los formatos no verbales (imagen, audio, gesticulación, contexto físico) para incrementar su comprensión del discurso verbal presente en estos recursos y avanzar en su aprendizaje del idioma. Sin duda esta característica está presente también en el aprendizaje presencial en el aula, pero quizás con menos relevancia.

- Plurilingüismo. En la red no hay fronteras o límites entre idiomas. Los aprendices emplean toda su competencia lingüística para adquirir nuevos conocimientos y habilidades en otras lenguas y contextos. Aldo no tiene ningún problema en usar el inglés para mejorar su ruso, siendo español.

- Aprendizaje social y situado. Los aprendices buscan espacios de afinidad en línea: redes sociales, repositorios y foros en los que puedan encontrar información y expertos sobre sus producciones culturales favoritas en la lengua meta. Aunque no participen activamente en estos espacios produciendo contenido, sí que utilizan sus recursos y aprovechan los conocimientos de la comunidad, de modo que mantienen un perfil participativo.

Finalmente, veamos algunas sugerencias sobre el impacto que pueden tener estas prácticas de aprendizaje informal y digital de idiomas dentro del aula, en la educación formal:

- Aceptación y valoración. Creemos que los docentes debemos aceptar, reconocer y valorar esas prácticas de aprendizaje informal que realizan muchos de nuestros aprendices, por su cuenta, fuera del ámbito de la enseñanza reglada. Sin duda son prácticas valiosas y rentables y son perfectamente compatibles con la actividad del aula. El conocimiento de lo que hacen los alumnos fuera del aula puede resultar muy útil para acercar más las clases a sus intereses o para tener más datos sobre su nivel de competencia lingüística en la lengua meta.

- Formación. Los docentes, como conocedores de la producción cultural en el idioma de enseñanza, pueden ayudar a los alumnos a desarrollar ese tipo de actividades: a identificar productos de su interés, a conocer los repositorios más importantes de cada cultura, a encontrar 
comunidades de seguidores de cantantes, películas, autores, cómics, etc. El docente puede actuar, de este modo, como un auténtico "mediador" o "curador" digital de contenidos para sus alumnos; puede formar al alumno para que sea mejor aprendiz por su cuenta, fuera de clase y en línea. Esa es una tendencia reciente y muy útil del aprendizaje de idiomas, que se ha formulado con el concepto de EPA (Entorno Personal de Aprendizaje; o PLE en inglés: Personal Learning Environment), que propone que los docentes contribuyan a desarrollar la conciencia sobre este entorno digital y la necesidad de que el aprendiz tome la iniciativa en su desarrollo para mejorar el aprendizaje de idiomas. Así, se podrían desarrollar propuestas didácticas para las clases de lengua que ayuden al aprendiz a usar el idioma fuera del aula y que contribuyan a conectar sus intereses personales con las producciones culturales en la cultura meta.

- ¿Integración? Otra cuestión más controvertida es la de la vinculación que estas prácticas informales de aprendizaje puedan tener con la enseñanza reglada, el currículum y las tradiciones didácticas del aula. Algunos docentes proponen integrar estas prácticas en clase, como en el caso del fanfic (Bringing fanfiction to the English Classroom) con la técnica del storytelling y sin entrar en los espacios privados de los alumnos. Experiencias como esta quedan recogidas, por ejemplo, en el blog de Shannon Sauro. Aunque tenemos ciertas dudas al respecto, puesto que incorporar lo vernáculo, privado y ocioso a un ámbito formal y académico puede ser una manera de desnaturalizar esas prácticas y de transformarlas en un sentido no necesariamente positivo. Recordemos que el aula es un espacio rígido, controlado por el docente, con unos horarios establecidos y un programa, mientras que esas prácticas en línea son vernáculas, autodirigidas por el aprendiz y que se integran en las rutinas ociosas personales. Es también posible que esa posible integración sea diferente con cada uno de los productos o actividades culturales: escribir fanfic es más cercano a practicar la escritura literaria -actividad académicaque ver dibujos animados o escuchar música hip-hop o rock. En definitiva, quizás sea más sensato no interferir directamente en el desarrollo de estas prácticas: observar y reconocer esas prácticas, considerarlas al planificar la actividad formal e incluso de formar al aprendiz para que pueda hacerlo mejor, pero de no acceder a esos espacios privados del alumno.

Sin duda en el futuro esas prácticas informales, digitales y sociales de aprendizaje de idiomas van a crecer. Vamos a necesitar más investigaciones al respecto de esta conexión entre el aprendizaje en línea y las aficiones de los participantes, y la actividad formal del aula experimentará todavía más cambios. Seguro que será para bien y para mejorar la tarea imprescindible de enseñar y aprender idiomas.

\section{Referencias}

Abrams, Z. I. (2014). Using film to provide a context for teaching L2 pragmatics. System, 46, pp. 5564.

Androutsopoulos, J. (2014). Languaging when contexts collapse: Audience design in social networking. Discourse, Context \& Media, 4, pp. 62-73. 
Bogomolov, A. N. (2008). Virtual learning of Russian as a foreign language. Maks Press (Богомолов, А. Н. (2008). Виртуальная среда обучения русскому языку как иностранному. М.: Макс Пресс).

Buck, A. (2012). Examining digital literacy practices on social network sites. Research of the teaching of English. 47(1), pp. 9-38.

Cassany, D. y Hernández D. (2011). Internet: 1; Escola: 0?, Articles, 53, pp. 25-34. Versión castellana: ¿Internet: 1; Escuela: 0?, Revista de Investigación Educativa, 14, recuperado de: https://goo.gl/8PWY1m.

Gassin, J. (1992). Interkinesics and Interprosodics in Second Language Acquisition. Australian Review of Applied Linguistics 15 (1), pp. 95-106.

Gee, J. P. (2004). Situated language and learning: A critique of traditional schooling. Psychology Press.

Hall, E. T. (1994). Proxémica. La nueva comunicación. Barcelona: Kairós, pp. 199-299.

Hoven, D. (1999). A model for listening and viewing comprehension in multimedia environments. Language Learning \& Technology, 3(1), pp. 88-103.

Hurley, D. S. (1992). Issues in teaching pragmatics, prosody, and non-verbal communication. Applied Linguistics, 13 (3), pp. 259-281.

Kellerman, S. (1992). "I See What You Mean": The role of kinesic behaviour in listening and implications for foreign and second language learning. Applied Linguistics, 13 (3), pp. 239-258.

Knobel, M., \& Lankshear, C. (2006). New literacies: everyday practices and classroom learning. Open University Press.

Knobel, M \& Lankshear, C. (2015). Researching and understanding new literacies from a social languages perspective. Futuuri! Language summer school and the language centre conference, disponible en: https://goo.gl/ouUfxW.

Lepänen, S. (2007). Youth language in media contexts: insights of the functions of English in Finland, World Englishes, 26, pp. 149-69

Nussbaum, L. (2014). Una didáctica del plurilingüisme. Bellaterra Journal of Teaching \& Learning Language \& Literature, 7 (3).

Rowsell, J., \& Walsh, M. (2011). Rethinking literacy education in new times: multimodality, multiliteracies, \& new literacies. Brock education, 21 (1), pp. 53-62. 
Shafirova, L. (2016). Aprender ruso en línea: perspectiva de los estudiantes. (Trabajo Final de Máster). Universitat Pompeu Fabra. Barcelona. Disponible en: https://goo.gl/SkR1Jo.

Thorne, S. L. (2008). Mediating Technologies and Second Language Learning. En Corio, J.; Knobel, M. Landkshear, C. Leu, D. ed. Handbook of Research on New Literacies. New York: Lawrence Erlbaum, pp. 417-448.

Thorne, S. L., Black, R. W., \& Sykes, J. M. (2009). Second language use, socialization, and learning in Internet interest communities and online gaming. The Modern Language Journal, 93 (s1), pp. 802-821.

Valero-Porras, M. J., \& Cassany, D. (2015). Multimodality and Language Learning in a Scanlation Community. Procedia-Social and Behavioral Sciences, 212, pp. 9-15. https://goo.gl/swqS2T

Zhang, L. T., \& Cassany, D. (2016). Fansubbing del español al chino: organización, roles y normes en la escritura colaborativa, Bid, 37, diciembre. https://goo.gl/zCTmtd

\section{Recursos web}

Top Ten Internet Languages - World Internet Statistics. (n.d.). Retrieved december 18, 2016, from https://goo.gl/vRj84P. 